\title{
Is Lung Clearance Index (LCI) Affected by the Severity of Lung Disease in
} CF?

\author{
Vasiliki Avramidou, Elpis Hatziagorou*, Asterios Kampouras, Vasiliki Georgopoulou, Fotis Kirvasilis and John Tsanakas \\ Respiratory and CF Unit, Aristotle University of Thessaloniki, 3rd Department in Paediatrics, Hippokration Hospital, Thessaloniki, Greece
}

\begin{abstract}
Background: LCl has been proven an effective tool in the detection of lung disease in CF.

Objectives: a) To assess the correlation of ventilation inhomogeneity indices with structural damages of the lung, among different groups of disease severity and b) To compare the associations among MBW parameters with spirometry and CT.
\end{abstract}

Method: Forty-four children and adolescents with CF participated in the study. Spirometry and multiple breath washout tests were performed. All children had a HRCT scan. The study population was divided into two groups, according to FEV $\%$ predicted values: Group A: $\geq 85 \%$ predicted (normal) and Group B: $40-84 \%$ predicted (mild-moderate disease).

Results: The patients' mean age was $12.9(5.67 ; 23.25)$ years, mean FEV1: $91.22 \pm 24.22 \%$ and mean LCl: $10.72 \pm$ 3.51. Children of Group A had significantly lower LCl, compared to Group B $(p<0.001)$. Among the whole study group all the ventilation inhomogeneity indices were correlated with $\mathrm{FVC} \%, \mathrm{FEV}_{1} \%$ and $\mathrm{FEF}_{50} \%$ and the severity and extent of bronchiectasis, the generation of bronchial division and the presence of emphysema $(p<0.05)$. Among patients with normal $\mathrm{FEV}_{1}, \mathrm{MBW}$ parameters showed stronger correlation with the structural changes of HRCT, while among patients with mild-moderate lung disease, they showed stronger correlation with spirometry.

Conclusion: MBW is a reliable method to assess the structural and functional lung disease in CF. However in mild disease ventilation inhomogeneity outcomes were better associated with CT changes, while in mild - moderate disease MBW outcomes were better associated with spirometry.

Keywords: Lung clearance index; Ventilation inhomogeneity; Cystic fibrosis; Bhalla score; Children; Multiple breath washout

\section{Introduction}

The persistent lung infection and inflammation, as well as the airway obstruction by viscid, dehydrated secretions lead to progressive lung disease with irreversible damages and decreased pulmonary function in patients with Cystic Fibrosis (CF) [1,2]. It is essential to have surrogate markers in order to define the disease severity status [3], to detect the lung destruction in earlier stages $[4,5]$ or to estimate the effectiveness of a treating intervention [6-12]. An appropriate outcome measure has to meet some criteria: It must reflect the presence and severity of the disease. That means that changes in the marker should closely match changes in real outcome. It also must be readily measurable and reflect significant clinical improvement as a response to a therapeutic regime [13].

Forced Expired Volume in $1^{\text {st }}$ second $\left(\mathrm{FEV}_{1}\right)$ measured with spirometry, has traditionally been used as the most common lung function parameter to assess the disease's impact on pulmonary function and is still recognized as a good predictor of outcome in cases with moderate-to-severe CF lung disease [14-16]. However, spirometry is difficult to be performed by preschoolers and infants, not only because it requires special equipment $[17,18]$, but also because $\mathrm{FEV}_{1}$ is now of less value in monitoring children with $\mathrm{CF}$, due to its lack to assess early or mild CF lung disease [19-22]. Structural damages may be present in High Resolution Computed Tomography (HRCT) in one third of CF children with normal spirometry [20-25].

High Resolution Computed chest Tomography (HRCT) is considered the gold standard for detecting bronchiectasis [26]. It can identify early and advanced structural damages [5,23,27-29] that correlate with the disease severity and progression among CF patients $[23,24,30]$. Various methods have been used to quantify structural abnormalities [25,31]. A few clinical trials have used HRCT as an outcome measure in young CF children $[1,25]$. Computed Tomography is a reproducible method but it cannot be repeated for monitoring CF lung disease in short time intervals because of the high radiation exposure. Although there has been an attempt to reduce the dose of radiation used in CT scanning in the last decade, its use should be restricted [31,32]. Furthermore, young children have to undergo sedation or general anesthesia in order to obtain high quality images of HRCT [29].

Computed Tomography scores have shown a good correlation with Lung Clearance Index (LCI) [5,32-34], a marker being measured by the Multiple Breath Washout method (MBW). MBW is a non-invasive and safe test for assessing ventilation inhomogeneity. LCI is the most common index of uneven ventilation distribution and has recently been proposed as a sensitive marker for the detection of early pulmonary changes in CF [35-37] and the assessment of treatment effectiveness [612]. LCI seems to allow earlier detection of disease, compared to FEV [36,37]. A significant advantage of LCI measurements is that it can be feasible from early age to adulthood and is not affected by age, weight, height and sex, with an exception for infants [38-41].

${ }^{*}$ Corresponding author: Elpis Hatziagorou, Respiratory and CF Unit, Aristotle University of Thessaloniki, 3rd Department in Paediatrics, Hippokration Hospital Thessaloniki, Greece, Tel: 00302310892400; Fax: 00302310892487; E-mail: ehatziagorou@gmail.com

Received December 22, 2016; Accepted January 30, 2017; Published January 31, 2017

Citation: Avramidou V, Hatziagorou E, Kampouras A, Georgopoulou V, Kirvasilis F, et al. (2017) Is Lung Clearance Index (LCl) Affected by the Severity of Lung Disease in CF? J Pulm Respir Med 7: 392. doi: 10.4172/2161-105X.1000392

Copyright: (c) 2017 Avramidou V, et al. This is an open-access article distributed under the terms of the Creative Commons Attribution License, which permits unrestricted use, distribution, and reproduction in any medium, provided the original author and source are credited. 
Little is known about associations of MBW with other lung outcome parameters in different disease stages. The aim of this study was a) to assess the correlation of partial indices of ventilation inhomogeneity with structural damages of the lung, among different groups of disease severity and b) to compare the associations among MBW parameters with spirometry and CT.

\section{Methods}

\section{Subjects}

Forty-eight CF children and adolescents that were followed up at the CF centre of Aristotle University of Thessaloniki were recruited in this prospective study from June 2012 to May 2015. Four patients were excluded because of their low lung function $\left(\mathrm{FEV}_{1}<40 \%\right.$ predicted) and their inability to complete the MBW test. Finally, a total of 44 eligible CF patients over the age of 5 years were recruited. This study was approved by the Ethical Committee of Aristotle University of Thessaloniki.

The study population was divided into two groups, according to $\mathrm{FEV}_{1} \%$ predicted values: a) $\geq 85 \%$ predicted (normal, Group A) and b) $<85 \%$ predicted (mild or moderate disease, Group B).

\section{Study design}

All patients were admitted in our department and were evaluated with spirometry, HRCT and multiple breath washout tests as part of their annual review. Patients were stable with no history of a pulmonary exacerbation or acute respiratory tract infection over the past month. Cough swab and sputum cultures were cultured and height, weight and BMI were recorded.

HRCT scans were performed on Asteion Toshiba CT scanner. Slices measuring $1.5 \mathrm{~mm}$ at $10 \mathrm{~mm}$ intervals were obtained during suspended respiration. Additional expiratory scans were obtained in older cooperative children at $20 \mathrm{~mm}$ intervals. Each CT scan was scored by two experienced and blinded radiologists using the modified "Bhalla" scoring system [42]. The mean value of the scores of the two blinded radiologists was calculated in order to establish most accurate results. The following findings were evaluated: severity and extent of bronchiectasis, severity of peribronchial thickening, generation of bronchial division involved, and extent of mucus plugging, sacculation or abscess formation, bullae, emphysema, atelectasis and consolidation. The higher value of Bhalla score, the more abnormalities in the lung are present.

Spirometry was performed according to ATS/ERS standards [43] using an electronic spirometer (Vitalograph 2120, Vitalograph Ltd Ennis, Ireland). Patients performed at least three efforts [44]. $\mathrm{FEV}_{1}$, Forced Vital Capacity (FVC) and Forced Expiratory 25-75 $\left(\mathrm{FEF}_{25-75}\right)$ results were automatically calculated. The results were expressed as percentage predicted.

MBW measurements were performed according to ATS/ERS standards [45] using a validated ultrasonic flow measuring system for measuring flow, volume and molecular mass (EXHALYZER D, Ecomedics, Switzerland) [46]. The duration of a MBW test is on average 2-5 min per maneuver in a healthy subject, but longer in subjects with airway obstruction [47], while LCI success rate ranges between $70 \%$ to 85\% in CF patients [48].

The apparatus consisted of a respiratory mass spectrometer and a flow-meter which recorded $\mathrm{N}_{2}$ concentration and inspiratory and expiratory flows close to mouth. The dead-space of reducer and bacterial filter was $20 \mathrm{ml}$ and $11 \mathrm{ml}$ respectively. Calibration of the system and environment setting correction were performed daily. During the
MBW tests the subject was sitting upright, wore a nose clip and was encouraged to breathe normally via a mouthpiece connected to a bacterial filter. When the patient achieved normal and steady breathing with steady tidal volumes and flows through the air supply (consisted of $78 \% \mathrm{~N}_{2}$ and $21 \% \mathrm{O}_{2}$ ), the $100 \% \mathrm{O}_{2}$ supply was on. As a consequence, the concentration of the tracer gas $\left(\mathrm{N}_{2}\right)$ was started to reduce. The washout phase continued until the end-tidal $\mathrm{N}_{2}$ concentration reached $1 / 40^{\text {th }}$ of its starting concentration, corresponding to approximately $2.5 \%$ of it. LCI is defined as a number of times lung turn overs (as represented by FRC) have to turn over to the clear the lungs from nitrogen $\left(\mathrm{N}_{2}\right)$. LCI $\left(\mathrm{LCI}_{2.5}\right.$ ) reflects $\mathrm{N}_{2}$ washout until $1 / 40^{\text {th }}$ of the starting $\mathrm{N}_{2}$ end-tidal concentration (cet), i.e., $2.5 \%$ and $\mathrm{LCI}_{5}$ reflects $\mathrm{N}_{2}$ washout until $1 / 20^{\text {th }}$ of the starting $\mathrm{N}_{2}$ concentration (Cet), i.e., 5\% [49-53]. So, the sicker the child is, the more air it must breathe to clear its lungs from the tracer gas.

FRC was calculated from the Cumulative Volume of Expired $\mathrm{N}_{2}$ divided by the difference between end-tidal gas concentration at the start and end of washout. The washout curve of the tracer gas during MBW represents the flow and gas concentration plotted against time. Moment Ratios (MR) are indices that have been defined to quantify the degree of ventilation inhomogeneity as can be plotted at the inert gas washout curve. The first and second moments $\left(\mu_{1}\right.$ and $\left.\mu_{2}\right)$ express the degree of skewing of the washout curve and are increased when there is an increased release of inert gas $\left(\mathrm{N}_{2}\right)$ at a later stage of the washout. A plot of concentration-normalized end-tidal concentration of $\mathrm{N}_{2}\left(\right.$ Cet $\left._{\mathrm{N}}\right)$ versus lung volume turnover number (TO) is necessary to calculate MR. The moments 0,1 and $2\left(\mu_{0}, \mu_{1}\right.$ and $\left.\mu_{2}\right)$ are determined by calculating the area under the curves for $\operatorname{Cet}_{\mathrm{N}}, \operatorname{Cet}_{\mathrm{N}} \mathrm{x}$ TO, $\operatorname{Cet}_{\mathrm{N}} \mathrm{x}(\mathrm{TO})^{2}$ plotted against TO, respectively. The ratios between the $1^{\text {st }}$ and the $0^{\text {th }}$ moments $\left(\mu_{1} /\right.$ $\left.\mu_{0}\right)$ and between the $2^{\text {nd }}$ and the $0^{\text {th }}$ moments $\left(\mu_{2} / \mu_{0}\right)$ are defined as MR. Increased values of the MR mean that greater proportion of lung units is slowly ventilated.

The normalized phase III slope (SnIII) extrapolated from a single- breath of MBW is a curve that has been used to assess specific mechanisms of ventilation inhomogeneity production and represents the tracer gas concentration plotted against expired volume. Two indices have been proposed [54] to assess the homogeneity of specific ventilation of partial lung units, Scond and Sacin. Scond is calculated as the linear regression of SnIII values between 1.5 and 6.0 TO (from the $6^{\text {th }}$ to the $15^{\text {th }}$ breath) and reflects the difference of gas transport through the conducting airways and Sacin, that is equal to the SnIII TO of the three first breaths minus the Scond contribution (based on the mean TO value of the three first breaths) and reflects the difference between parallel units to the acini $[38,40,45]$.

\section{Statistical analysis}

Descriptive statistics were used to describe the study population. The patients served as their own control subjects. Normality was determined using the Kolmogorov-Smirnov test and then Pearson or Spearman correlation analysis was used to investigate correlations between spirometric, MBW and Bhalla score parameters. The Student T-test was used to compare the LCI values between different groups. A multivariate regression with stepwise method was performed including every Bhalla score parameter as a dependent variable and lung function parameters as independents variables. The level of significance was taken as $\mathrm{p}<0.05$. Statistical analysis was performed using SPSS for Windows version 20.0 (SPSS IBM SPSS Statistics 20).

\section{Results}

A total of $44 \mathrm{CF}$ children and adolescents (23 females and 21 
Citation: Avramidou V, Hatziagorou E, Kampouras A, Georgopoulou V, Kirvasilis F, et al. (2017) Is Lung Clearance Index (LCl) Affected by the Severity of Lung Disease in CF? J Pulm Respir Med 6: 392. doi: 10.4172/2161-105X.1000392

Page 3 of 7

males) with a mean (range) age of 12.9 years $(5.67 ; 23.25)$ were recruited. The demographic and anthropometric characteristics of the patients that participated in the study are shown in Table 1 . The mean (range) BMI was 18.34 (11.6; 26.4). Fifteen $(34.09 \%)$ patients were $\Delta$ F508 homozygous and $18(40.90 \%)$ were $\Delta$ F508 heterozygous. The majority of patients $(95.45 \%)$ were pancreatic insufficient and $38.6 \%$ were chronically colonized with Pseudomonas aeruginosa. Baseline spirometric and MBW parameters are shown in Table 1. The study group included 27 children (61.4\%) with normal spirometry $\left(\mathrm{FEV}_{1} \geq\right.$ $85 \%$ of predicted, Group A) and $17(38.6 \%)$ with mild or moderate lung disease $\left(\mathrm{FEV}_{1}: 40-85 \%\right.$ of predicted, Group B).

The mean (range) total Bhalla score was $7.35(0 ; 18)$. The most common abnormalities identified by the partial Bhalla score parameters were bronchiectasis in 35 (79.5\%) patients and peribronchial thickening in 28 (63.6\%). Twenty four (54.5\%) patients had emphysema and collapse or consolidation and seventeen (38.6\%) had mucus plugging. There were $9(20.5 \%)$ patients who had sacculations and $3(6.8 \%)$ who had bullaes.

LCI was statistically significant different according to the lung disease severity: The mean LCI of patients chronically or intermitted colonized with Pseudomonas aeruginosa was worse than patients free of Pseudomonas aeruginosa (LCI: 13.47 vs. 9.49 vs. 8.58, $\mathrm{p}<0.001$ ). Additionally, Group A (normal) had significantly lower LCI, in comparison to Group B (mild and moderate lung disease) $(9.1 \pm 2.5 v s$. $13.3 \pm 3.3, \mathrm{p}<0.001$ ) (Figure 1).

\section{Correlations of LCI and spirometry/Bhalla score among the total study group}

Correlation analysis among the total population showed significant correlation between LCI and spirometric parameters: $\mathrm{FVC} \%, \mathrm{FEV}_{1} \%$ and $\mathrm{FEF}_{25-75} \%$ of predicted $(\mathrm{p}<0.001)$. Twenty patients $(47.6 \%)$ with normal $\mathrm{FEV}_{1} \%$ had abnormal LCI. A significant correlation was found between LCI and total Bhalla score $\left(\mathrm{p}<0.001, \mathrm{r}^{2}: 0.846\right)$ (Figure 2). Several significant correlations were detected between LCI and the partial Bhalla score parameters: severity of bronchiectasis, extent of bronchiectasis, generation of bronchial divisions $(\mathrm{p}<0.001)$, presence of emphysema $(\mathrm{p}<0.01)$ and mucus plugging $(\mathrm{p}<0.05)$. The sensitivity of the LCI to detect structural lung damage was $96.8 \%$, the specificity was $83.3 \%$ and the positive predictive value was $93.4 \%$.

Multivariate regression analysis using stepwise method of the total population showed that LCI was the only predictor of most of the partial parameters of Bhalla score: severity of bronchiectasis $\left(\mathrm{r}^{2}=0,575\right.$, $\mathrm{p}<0.001$, 95\% CI:0.127; 0.220), extent of bronchiectasis $\left(\mathrm{r}^{2}=0,376\right.$, $\mathrm{p}<0.001,95 \%$ CI:0.133; 0.310), peribronchial thickening $\left(\mathrm{r}^{2}=0,395\right.$, $\mathrm{p}<0.001,95 \% \mathrm{CI}: 0.084 ; 0.190)$, generation of bronchial divisions $\left(\mathrm{r}^{2}=0.694, \mathrm{p}<0.001,95 \%\right.$ CI:0.197; 0.300), extent of mucus plugging $\left(\mathrm{r}^{2}=0,343, \mathrm{p}<0.001,95 \% \mathrm{CI}: 0.072 ; 0.182\right)$ and sacculation or abscess formation $\left(\mathrm{r}^{2}=0.279, \mathrm{p}<0.001,95 \%\right.$ CI:0.036; 0.107) (Figure 3).

\section{Correlations of LCI and spirometry/Bhalla score in Group A and $B$}

LCI was correlated with $\mathrm{FEV}_{1} \%$ predicted (r:-0.383, p=0.049),

\begin{tabular}{|c|c|c|c|c|c|c|c|}
\hline \multirow[t]{2}{*}{ Population characteristics } & \multicolumn{2}{|c|}{ Total population } & \multicolumn{2}{|c|}{$\begin{array}{c}\text { Group A } \\
\text { FEV }_{1} \geq 85 \%\end{array}$} & \multicolumn{2}{|c|}{$\begin{array}{c}\text { Group B } \\
\text { FEV }_{1} 40-84 \%\end{array}$} & \multirow[t]{2}{*}{$\mathbf{p}$} \\
\hline & Mean or $\mathbf{N}$ & SD or $\%$ & Mean & SD or $\%$ & Mean & SD or $\%$ & \\
\hline Number of patients, males $\%$ & 44 & & 27 & $61.4 \%$ & 17 & $38.6 \%$ & 0.056 \\
\hline Age (years) (mean, SD) & 12.93 & 5.23 & 11.4 & 4.48 & 15.36 & 5.53 & $0.013^{*}$ \\
\hline Height $(\mathrm{cm})($ mean, SD) & 144.45 & 144.45 & 140.67 & 18.87 & 150.47 & 20.03 & 0.109 \\
\hline z-score (mean, SD) & -0.41 & 1.65 & -0.28 & 1.81 & -0.73 & 1.16 & 0.483 \\
\hline Weight (kg) (mean, SD) & 39.98 & 39.98 & 37.41 & 13.18 & 44.06 & 17.22 & 0.155 \\
\hline z-score (mean, SD) & 0.19 & 1.87 & 0.77 & 1.49 & -2.12 & 1.55 & $0.010^{*}$ \\
\hline $\mathrm{BMI}\left(\mathrm{kg} / \mathrm{m}^{2}\right)($ mean, SD) & 18.34 & 3.03 & 18.26 & 2.59 & 18.48 & 3.71 & 0.817 \\
\hline z-score (mean, SD) & -0.11 & 1.48 & 0.30 & 1.47 & -1.03 & 1.09 & 0.016 \\
\hline$\Delta \mathrm{F} 508$ homozygous $(\mathrm{N}, \%)$ & 15 & $34.09 \%$ & 8 & $29.6 \%$ & 7 & $41.2 \%$ & 0.078 \\
\hline$\Delta \mathrm{F} 508$ heterozygous $(\mathrm{N}, \%)$ & 18 & $40.9 \%$ & 11 & $40.7 \%$ & 7 & $41.2 \%$ & 0.604 \\
\hline \multicolumn{8}{|l|}{ P. aeruginosa status: (N, \%) } \\
\hline Negative & 15 & $34.1 \%$ & 15 & $55.5 \%$ & 0 & 0 & $0.001^{*}$ \\
\hline Intermitent & 12 & $27.2 \%$ & 8 & $29.6 \%$ & 4 & $23.5 \%$ & 0.231 \\
\hline Chronic & 17 & $38.6 \%$ & 4 & $14.8 \%$ & 13 & $76.5 \%$ & $0.001^{*}$ \\
\hline Pancreatic insufficient $(\mathrm{N}, \%)$ & 42 & $95.45 \%$ & 25 & $92.6 \%$ & 17 & 1 & 0.251 \\
\hline Bhalla score (mean, SD) & 7.75 & 4.73 & 5.70 & 4.25 & 11.00 & 3.54 & $0.000 \dagger$ \\
\hline FRC (mean, SD) & 2.430 & 1.134 & 2.129 & 0.994 & 2.907 & 1.206 & 0.25 \\
\hline LCl_(mean, SD) & 10.72 & 3.51 & 9.09 & 2.54 & 13.31 & 3.31 & $0.000 \dagger$ \\
\hline LCl_5 (mean, SD) & 6.59 & 2.07 & 5.76 & 1.69 & 7.90 & 1.98 & $0.000 \dagger$ \\
\hline Scond (mean, SD) & 0.024 & 0.029 & 0.018 & 0.178 & 0.034 & 0.041 & 0.097 \\
\hline Sacin (mean, SD) & 0.089 & 0.085 & 0.062 & 0.066 & 0.133 & 0.096 & $0.005^{*}$ \\
\hline M1/M0 (mean, SD) & 2.32 & 0.79 & 1.98 & 0.51 & 2.828 & 0.88 & $0.002^{*}$ \\
\hline M2/M0 (mean, SD) & 12.62 & 9.4 & 8.75 & 5.42 & 18.76 & 11.13 & $0.002^{*}$ \\
\hline FVC \% (mean, SD) & 92.1 & 18.73 & 102.5 & 11.99 & 75.56 & 15.39 & $0.000 \dagger$ \\
\hline FEV1\% (mean, SD) & 91.2 & 24.22 & 107.19 & 13.25 & 65.86 & 13.33 & $0.000 \dagger$ \\
\hline FEF50\% (mean, SD) & 86.56 & 36.86 & 108.34 & 22.49 & 51.98 & 27.53 & $0.000 \dagger$ \\
\hline
\end{tabular}

$+p \leq 0.001 ;{ }^{*} p<0.05$ 


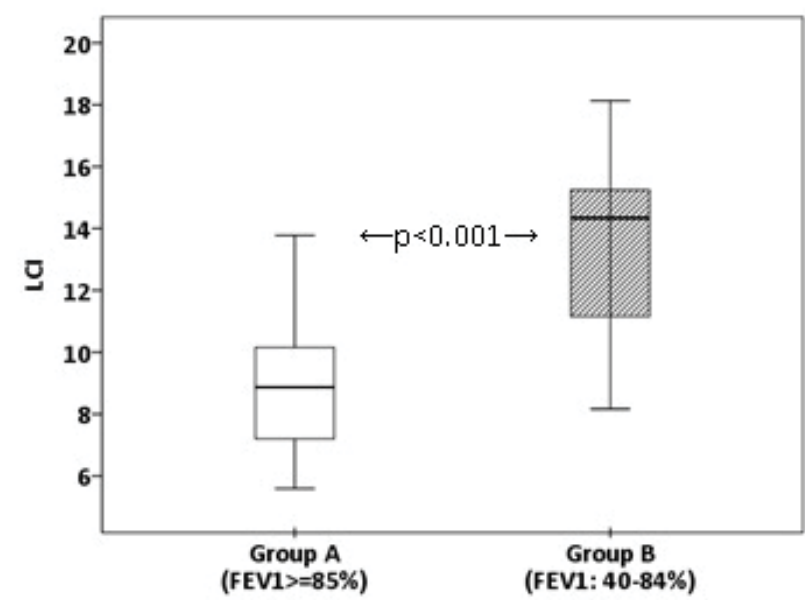

Figure 1: Group A (normal $\mathrm{FEV}_{1}$ ) had significantly lower $\mathrm{LCl}$, in comparison to group $B$ (mild and moderate lung disease) ( $\mathrm{LCl}: 9.1 \pm 2.5$ vs. $13.3 \pm 3.3$ $\mathrm{p}<0.001)$.
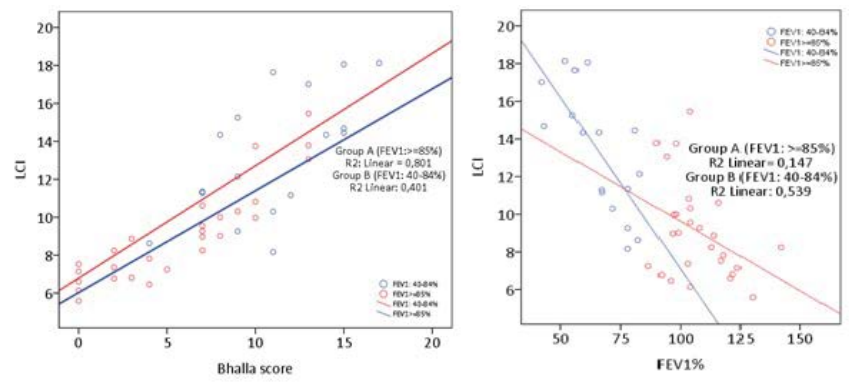

Figure 2: Correlations between: $\mathrm{A}) \mathrm{LCl}$ and Bhalla score and $\mathrm{B}) \mathrm{LCl}$ and $\mathrm{FEV}$, in the whole study population $(p<0.001)$.
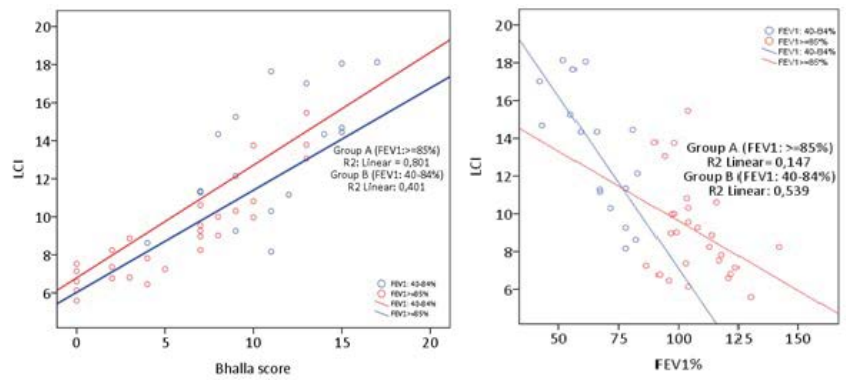

Figure 3: Regression analysis between $\mathrm{A}$ ) $\mathrm{LCl}$ and Bhalla score and $\mathrm{B}$ ) LC and $\mathrm{FEV}_{1}$ in both groups.

the severity and extent of bronchiectasis $(\mathrm{p}<0.001)$ and generation of bronchial divisions $(\mathrm{p}<0.001)$ among patients with normal spirometry (Group A). In group A, the sensitivity of the LCI to detect structural lung damage was $93.3 \%$, the specificity was $83.3 \%$ and the positive predictive value was $87.5 \%$. Among patients with mild to moderate disease (Group B), LCI was correlated with $\mathrm{FEV}_{1} \%(\mathrm{r}:-0.734, \mathrm{p}=0.001)$, FEF50\% ( $\mathrm{r}:-0.569, \mathrm{p}=0.017$ ), the severity ( $\mathrm{r}: 0.565, \mathrm{p}=0.018$ ) and extent of bronchiectasis ( $\mathrm{r}: 0.570, \mathrm{p}=0.017)$ and the generation of bronchial divisions ( $\mathrm{r}: 0.570, \mathrm{p}=0.017)$. The sensitivity of the LCI to detect structural lung damage in Group B was $100 \%$ and the positive predictive value was $100 \%$.
Correlations of the rest of MBW parameters and spirometry/ Bhalla score correlation analysis among the total population showed significant correlation between $\mathrm{LCI}_{5}, \mu_{1} / \mu_{0}$ and $\mu_{2} / \mu_{0}$ and spirometric parameters: $\mathrm{FVC} \%, \mathrm{FEV}_{1} \%$ and $\mathrm{FEF}_{25-75} \%$ of predicted $(\mathrm{p}<0.001)$. Several significant correlations were detected between $\mathrm{LCI}_{5}, \mu_{1} / \mu_{0}$ and $\mu_{2} / \mu_{0}$ and the partial Bhalla score parameters: severity of bronchiectasis, extent of bronchiectasis, generation of bronchial divisions $(\mathrm{p}<0.001)$, presence of emphysema $(\mathrm{p}<0.01)$ and mucus plugging $(\mathrm{p}<0.05)$.

In Group A (patients with normal spirometry) all the indices of MBW showed a good correlation with the severity and extent of bronchiectasis and generation of bronchial divisions $\left(\mathrm{LCI}_{5}(\mathrm{p}<0.05)\right.$, $\mu_{1} / \mu_{0}(\mathrm{p}<0.001)$ and $\left.\mu_{2} / \mu_{0}(\mathrm{p}<0.001)\right)$. Among patients with mild to moderate disease (Group B) LCI $_{5}$ correlated with FVC\% (r:-0.533, $\mathrm{p}=0.028), \mathrm{FEV}_{1} \%(\mathrm{r}:-0.804, \mathrm{p}<0.001), \mathrm{FEF}_{50} \%(\mathrm{r}:-0.512, \mathrm{p}=0.036)$ and the severity of bronchiectasis $(\mathrm{r}: 0.501, \mathrm{p}=0.041), \mu_{1} / \mu_{0}$ correlated with $\mathrm{FEV}_{1} \%(\mathrm{r}:-0.648, \mathrm{p}=0.005)$ and $\mathrm{FEF}_{50} \%(\mathrm{r}:-0.754, \mathrm{p}<0.001)$, the extent of bronchiectasis and the generation of bronchial divisions ( $\mathrm{p}: 0.519$, $\mathrm{r}: 0.033), \mu_{2} / \mu_{0}$ with $\mathrm{FEV}_{1} \%$ ( $\left.\mathrm{r}:-0.703, \mathrm{p}=0.002\right), \mathrm{FEF}_{50} \%$ (r:-0.726, $\mathrm{p}=0.001$ ), the extent of bronchiectasis and the generation of bronchial divisions ( $\mathrm{r}: 0.519, \mathrm{p}=0.033)$ and Sacin with $\mathrm{FEV}_{1} \%(\mathrm{r}:-0.659, \mathrm{p}=0.004)$, $\mathrm{FEF}_{50} \%(\mathrm{r}:-0.511, \mathrm{p}=0.036)$.

\section{Discussion}

This study assessed the correlation of MBW parameters with conventional lung function parameters measured with spirometry and structural damages that were assessed by HRCT. It was demonstrated that classic ventilation inhomogeneity indices i.e., LCI, $\mu_{1} / \mu_{0} \mu_{2} / \mu_{0}$, Scond and Sacin, as well as the recently used LCI $_{5}$ were well correlated with $\mathrm{FVC} \%, \mathrm{FEV}_{1} \%$ and $\mathrm{FEF}_{50} \%$ and the severity and extent of bronchiectasis, the generation of bronchial division and the presence of emphysema. To our knowledge, this is the first study that: a) investigates the correlation between MBW parameters and CT parameters, among different groups of lung disease severity and b) explores the relationship of LCI $_{5}$ with spirometric and CT parameters. It was shown that MBW parameters had stronger correlation with structural changes on HRCT among patients with normal $\mathrm{FEV}_{1} \%$, while $\mathrm{MBW}$ parameters had stronger correlation with spirometry among patients with mild or moderate lung disease. Therefore, LCI was a good predictor of structural damages with high sensitivity and showed a positive predictive value in both groups.

Chronic lung disease remains the most common cause of morbidity and mortality among CF patients [55]. Measurement of lung function is significant to assess the severity and determine the progression of $\mathrm{CF}$ lung disease [3]. Spirometry is the most common widely used method for clinical monitoring of CF lung disease and the equipment is available in most respiratory centers. $\mathrm{FEV}_{1}$ has proved to be a good predictor in subjects with moderate-to-severe CF lung disease [14,17,47,48], but it doesn't seem to be sensitive in earlier stages of the disease, as it is possible to have normal $\mathrm{FEV}_{1}$ values when structural damages have already been developed on HRCT [20,23-25]. Additionally, spirometry demands active cooperation to achieve technically acceptant curves, which may be difficult for infants and preschoolers [36,37].

HRCT is the reference method to detect bronchiectasis, the most important component of CF lung damage $[22,56]$. It has been more sensitive than $\mathrm{FEV}_{1}$ for early detection of CF lung disease [5,23,24,2730]. HRCT detects structural airways damages, but its use has been restricted due to high levels of radiation exposure [57] and it has been suggested not to perform CT scans more than once every 2 or 3 years, especially in patients without respiratory symptoms [3].

During last decades, an increased interest for MBW method among 
patients suffering from CF has been noted [3,4,33-34,58-63] MBW is a non-invasive method, feasible to be performed and without the risk of radiation exposure [64]. A lot of studies have suggested that LCI has the advantage over $\mathrm{FEV}_{1}$ to detect $\mathrm{CF}$ lung disease in earlier stages [21,36,38,64-68]. A more sophisticated analysis of the SnIII has revealed the Scond and Sacin, as indices to detect the mechanisms of ventilation inhomogeneity and the location of the different ventilated lung units. So, the Scond estimates the Convection- dependent Inhomogeneity (CDI) through the conducting airways and the Sacin estimates the Diffusion Convection Interaction Dependent Inhomogeneity (DCDI) at the mouth of the acini $[38,40,47]$. LCI is easily applicable in infants and preschoolers because passive cooperation is only required during measurement. Moment Ratios (MR) calculated with this method, has been also used as indices of uneven ventilation distribution in later stages of the gas washout [4] and is suitable to differentiate health from disease [69]. In the present study a strong correlation was shown between ventilation inhomogeneity indices LCI, LCI,$\mu_{1} / \mu_{0}$ and $\mu_{2} / \mu_{0}$ and spirometric parameters $\mathrm{FVC} \%, \mathrm{FEV}_{1} \%$ and $\mathrm{FEF}_{50} \%$ in the total population.

As far as the correlation with CT is concerned, LCI, LCI,$\mu_{1} /$ $\mu_{0}$ and $\mu_{2} / \mu_{0}$ were found to have a close relationship with the severity and extent of bronchiectasis, the generation of bronchial division, the presence of mucus plugging and both LCI and Moments Ratio (MR) with emphysema. LCI also showed high sensitivity (92.3\%) and positive predictive value (97.3\%) to detect structural damages on HRCT. Consequently, LCI can be used as a reliable index for monitoring lung structure.

Half of the patients of Group A with normal spirometry were found to have an abnormal LCI. This finding confirms the greater sensitivity of LCI to detect changes in the airways, compared to spirometry. Changes in small airway dimensions, due to pathological situations, affect the distribution of ventilation among different parallel pathways and have an impact on LCI. However these small changes can contribute to the overall resistance and volumes of respiratory tract and cannot be detected by $\mathrm{FEV}_{1}$ [40].

Among patients of Group A with normal $\mathrm{FEV}_{1}$, a better correlation was found between MBW and CT parameters than $\mathrm{FEV}_{1}$ and CT parameters. This illustrates that an abnormal LCI in CF patients with normal $\mathrm{FEV}_{1}$ predicts with high sensitivity the structural damages of the lung. These findings are in accordance to the findings of Ellemunter et al. [22] who showed that $80 \%$ of patients with normal $\mathrm{FEV}_{1}$ had an abnormal LCI and pathological changes on HRCT. Gustaffson et al. [20] also showed that LCI had a greater sensitivity (85-94\%) to detect bronchiectasis and other structural damages $v s$. FEV $(85-94 \%)$.

On the contrary, not only LCI, but also LCI $_{5} \mu_{1} / \mu_{0} \mu_{2} / \mu_{0}$ and Sacin were significantly correlated with $\mathrm{FEV}_{1} \%$ and $\mathrm{FEF}_{50} \%(\mathrm{p}<0.05)$ among patients of Group B with mild to moderate lung disease. Especially, $\mathrm{LCI}$ and $\mathrm{LCI}_{5}$ were strongly correlated with $\mathrm{FEV}_{1} \%(\mathrm{p} \leq 0.001)$. Low spirometry reflects impaired lung function that is usually combined with severe ventilation heterogeneity. Significant correlation were found between LCI, $\mathrm{LCI}_{5}$ and $\mu_{2} / \mu_{0}$ with bronchiectasis and generation of bronchial division $(\mathrm{p}<0.05)$.

It is very important to detect lung abnormalities in early stages of lung disease before irreversible structural damages become present, in order to the prognosis of CF patients. LCI has been used as a feasible tool that can assess early lung disease. Gustafsson et al. [20] retrospectively analyzed data of 44 CF patients aged 5-19 year old with a wide range of lung function $\left(\mathrm{FEV}_{1}=44-127 \%\right)$ and concluded that a normal LCI almost excludes HRCT abnormalities [20]. Although they assessed CT scans with Brody score the data of our study agree with them as LCI was proved to be the only predictor of structural changes on HRCT in both the total population and sub-groups. The results of Group A were in accordance to Ellemunter's et al. [22] study that evaluated prospectively 34 patients (6-26 years) with normal spirometry. They supported that structural damages are unlikely if a normal LCI is measured. In agreement with their study, we showed a significant relationship between ventilation inhomogeneity indices and presence of bronchiectasis. Consequently, MBW measurement may be used as an appropriate method for monitoring the progression of CF lung disease mainly in preschoolers and school age children [5], while a normal LCI may prevent the radiation exposure from HRCT. In the present study, both LCI $_{5}$ that assesses ventilation inhomogeneity in an earlier time of the gas washout, and MR that represent the later phase of washout, seem to have a good relationship with lung structure and function, like LCI. However, they have not been proved significant predictors of lung damage.

However, there were limitations to this study. 1) When dividing patients into two groups the sample size of Group B with mild to moderately impaired spirometry, was limited and there was a wide range of $\mathrm{FEV}_{1} \%$. 2) The phase III slope requires fixed tidal volumes during single breaths; that is usually not practicable for young children. So, Scond and Sacin values may be unreliable. 3) Completing MBW test is difficult and not well tolerated for patients with severe lung disease. Our study confirmed the $\mathrm{LCI}_{5}$ reliability to assess CF respiratory tract, as Yammine et al. [53] has recommended. Longitudinal data with a larger sample size is required to confirm the value of $\mathrm{LCI}_{2.5}$ among CF patients with abnormal spirometry and to investigate the value of $\mathrm{LCI}_{5}$ in advanced lung disease where MBW is time consuming.

\section{Conclusion}

In conclusion, MBW parameters (LCI LCI $, \mu_{1} / \mu_{0}, \mu_{2} / \mu_{0}$, Scond and Sacin) were significantly correlated with spirometric and partial parameters of Bhalla score on HRCT. So, MBW is a reliable method of assessment the structural and functional changes of respiratory tract. However, in mild disease ventilation inhomogeneity indices were better associated with CT changes, while in mild - moderate disease MBW indices were better associated with spirometry. The LCI was showed to predict CF structural lung damage among CF patients with normal and mild - moderate disease.

\section{Contributor's List}

EH, VA and JT had full access to all of the data in the study and take responsibility for the integrity of the data and the accuracy of the data analysis. EH, VA, AK and JT contributed substantially to the study design, data analysis and interpretation. VA performed the MBW measurements, while AK performed the CPET measurements. VG performed Bhalla scoring of the HRCT scans. All the authors contributed to the writing of the manuscript. EH and JT reviewed and edited the manuscript. EH and JT are guarantors.

\section{Conflicts of Interest}

All authors would like to confirm that there is nothing to declare.

\section{Ethics Approval}

Aristotle University of Thessaloniki Medical School Ethics Committee (IRB file No. 1/8-11-2012). 
Citation: Avramidou V, Hatziagorou E, Kampouras A, Georgopoulou V, Kirvasilis F, et al. (2017) Is Lung Clearance Index (LCl) Affected by the Severity of Lung Disease in CF? J Pulm Respir Med 6: 392. doi: 10.4172/2161-105X.1000392

\section{References}

1. Davis SD, Fordham LA, Brody AS, Noah TL, Retsch-Bogart GZ, et al. (2007) Computed tomography reflects lower airway inflammation and tracks changes in early cystic fibrosis. Am J Respir Crit Care Med 175: 943-950.

2. Martínez TM, Llapur CJ, Williams TH, Coates C, Gunderman R, et al. (2005) High-resolution computed tomography imaging of airway disease in infants with cystic fibrosis. Am J Respir Crit Care Med 172: 1133-1138.

3. Davies JC, Cunningham S, Alton EWFW, Innes JA (2008) Lung clearance index in CF: A sensitive marker of lung disease severity. Thorax 63: 96-97.

4. Hall GL, Logie KM, Parsons F, Schulzke SM, Nolan G, et al. (2011) Air trapping on chest $\mathrm{CT}$ is associated with worse ventilation distribution in infants with cystic fibrosis diagnosed following newborn screening. PLoS ONE 6: e23932.

5. Ramsey KA, Rosenow T, Turkovic L (2016) Lung clearance index and structural lung disease on computed tomography in early cystic fibrosis. Am J Respir Crit Care Med 193: 60-67.

6. Amin R, Subbarao P, Jabar A, Balkovec S, Jensen R, et al. (2010) Hypertonic saline improves the $\mathrm{LCl}$ in paediatric patients with $\mathrm{CF}$ with normal lung function. Thorax 65: 379-383.

7. Ellemunter H, Eder J, Fuchs S, Gappa M, Steinkamp G (2016) Long-term improvement of lung clearance index in patients with mild cystic fibrosis lung disease: Does hypertonic saline play a role? J Cyst Fibros 15: 123-126.

8. Subbarao P, Stanojevic S, Brown M, Jensen R, Rosenfeld M, et al. (2013) Lung clearance index as an outcome measure for clinical trials in young children with cystic fibrosis. A pilot study using inhaled hypertonic saline. Am J Respir Crit Care Med 188: 456-460.

9. Amin R, Subbarao P, Lou W, Jabar A, Balkovec S, et al. (2011) The effect of dornase alfa on ventilation inhomogeneity in patients with cystic fibrosis. Eur Respir J 37: 806-812

10. Davies J, Sheridan H, Bell N, Cunningham S, Davis SD, et al. (2013) Assessment of clinical response to ivacaftor with lung clearance index in cystic fibrosis patients with a G551D-CFTR mutation and preserved spirometry: a randomised controlled trial. Lancet Respir Med 1: 630-638.

11. Kane M, Gonska T, Jensen R, Avolio J, Klingel M, et al. (2016) Lung clearance index response in patients with CF with class III CFTR mutations. Thorax 71 : 476-477.

12. Hall GL, Stocks J (2011) Intervention trials and ventilation distribution in mild cystic fibrosis lung disease: will it all come out in the wash? Eur Respir J 37 757-759.

13. Fleming TR, Powers JH (2012) Biomarkers and surrogate endpoints in clinical trials. Stat Med 31: 2973-2984.

14. Aurora $P$, Wade A, Whitmore $P$, Whitehead $B(2000)$ A model for predicting life expectancy of children with cystic fibrosis. Eur Respir J 16: 1056-1060.

15. Hayllar KM, Williams SG, Wise AE, Pouria S, Lombard M, et al. (1997) A prognostic model for the prediction of survival in cystic fibrosis. Thorax 52: 313-317.

16. Sharma R, Florea VG, Bolger AP, Doehner W, Florea ND, et al. (2001) Wasting as an independent predictor of mortality in patients with cystic fibrosis. Thorax 56: 746-750.

17. Eigen H, Bieler H, Grant D, Christoph K, Terrill D, et al. (2001) Spirometric pulmonary function in healthy preschool children. Am J Respir Crit Care Med 163: 619-623.

18. Stocks J, Sly PD, Morris MG, Frey U (2000) Standards for infant respiratory function testing: what(ever) next? Eur Respir J 16: 581-584

19. Lum S, Gustafsson P, Ljungberg H, Hülskamp G, Bush A, et al. (2007) Early detection of cystic fibrosis lung disease: multiple-breath washout versus raised volume tests. Thorax 62: 341-347.

20. Gustafsson PM, De Jong PA, Tiddens HA, Lindblad A (2008) Multiple-breath inert gas washout and spirometry versus structural lung disease in cystic fibrosis. Thorax 63: 129-134.

21. Loeve M, Krestin GP, Rosenfeld M, De Bruijne M, Stick SM, et al. (2012) Chest computed tomography; a validated surrogate endpoint of cystic fibrosis lung disease? Eur Respir J 42: 844-857.

22. Ellemunter H, Fuchs SI, Unsinn KM, Freund MC, Waltner-Romen M, et al. (2010) Sensitivity of lung clearance index and chest computed tomography in early CF lung disease. Respir Med104: 1834-1842.
23. de Jong PA, Lindblad A, Rubin L, Hop WC, de Jongste JC, et al. (2006) Progression of lung disease on computed tomography and pulmonary function tests in children and adults with cystic fibrosis. Thorax 61: 80-85.

24. de Jong PA, Nakano Y, Lequin MH, Mayo JR, Woods R, et al. (2004) Progressive damage on high resolution computed tomography despite stable lung function in cystic fibrosis. Eur Respir J 23: 93-97.

25. Tiddens HA (2002) Detecting early structural lung damage in cystic fibrosis Pediatr Pulmonol 34: 228-231.

26. Hansell DM (1998) Bronchiectasis. Radiol Clin North Am 36: 107-128.

27. Brody AS, Klein JS, Molina PL, Quan J, Bean JA, et al. (2004) Highresolution computed tomography in young patients with cystic fibrosis: Distribution of abnormalities and correlation with pulmonary function tests. J Pediatr 145: 32-38

28. Dodd JD, Barry SC, Barry RB, Gallagher CG, Skehan SJ, et al. (2006) Thinsection CT in patients with cystic fibrosis: correlation with peak exercise capacity and body mass index. Radiology 240: 236-245.

29. Long FR, Castile RG, Brody AS, Hogan MJ, Flucke RL, et al. (1999) Lungs in infants and young children: improved thin-section CT with a non-invasive controlled-ventilation technique-initial experience1. Radiology 212: 588-593.

30. Brody AS, Sucharew H, Campbell JD, Millard SP, Molina PL, et al. (2005) Computed tomography correlates with pulmonary exacerbations in children with cystic fibrosis. Am J Respir Crit Care Med172: 1128-1132.

31. de Jong PA, Nakano Y, Lequin MH, Tiddens HA (2006) Dose reduction for C in children with cystic fibrosis: is it feasible to reduce the number of images per scan? Pediatr Radiol 36: 50-53.

32. de Jong PA, Long FR, Nakano Y (2006) Computed tomography dose and variability of airway dimension measurements: how low can we go? Pediatr Radiol 36: 1043-1047.

33. O'Connor OJ, Vandeleur M, McGarrigle AM, Moore N, McWilliams SR, et al. (2010) Development of low-dose protocols for thin-section CT assessment of cystic fibrosis in pediatric patients. Radiology 257: 820-829.

34. Owens CM, Aurora P, Stanojevic S, Bush A, Wade A, et al. (2011) Lung clearance index and HRCT are complementary markers of lung abnormalities in young children with CF. Thorax 66: 481-488.

35. Aurora P, Bush A, Gustafsson P, Oliver C, Wallis C, et al. (2005) Multiple-breath washout as a marker of lung disease in preschool children with cystic fibrosis. Am J Respir Crit Care Med 171: 249-256.

36. Gustafsson PM, Aurora P, Lindblad A (2003) Evaluation of ventilation maldistribution as an early indicator of lung disease in children with cystic fibrosis. Eur Respir J 22: 972-979.

37. Kraemer R, Blum A, Schibler A, Ammann RA, Gallati S (2005) Ventilation inhomogeneities in relation to standard lung function in patients with cystic fibrosis. Am J Respir Crit Care Med 171: 371-378.

38. Aurora PKW, Stocks J. (2005) Gas mixing efficiency from birth to adulthood measured by multiple-breath washout. Respir Physiol Neurobiol 148: 125-139.

39. Gustafsson PM (2005) Inert gas washout in preschool children. Paediatr Respir Rev 6: 239-245

40. Robinson PD, Goldman MD, Gustafsson PM (2009) Inert gas washout: theoretical background and clinical utility in respiratory disease. Respiration 78: $339-355$

41. Fuchs SI, Eder J, Ellemunter H, Gappa M (2009) Lung clearance index: Normal values, repeatability, and reproducibility in healthy children and adolescents. Pediatr Pulmonol 44: 1180-1185.

42. Bhalla M, Turcios N, Aponte V, Jenkins M, Leitman BS, et al. (1991) Cystic fibrosis: scoring system with thin-section CT. Radiology 179: 783-788.

43. Beydon N, Davis DS, Lombardi E, Allen JL, Arets HG, et al. (2007) An official American Thoracic Society/European Respiratory Society statement: Pulmonary function testing in preschool children. Am J Respir Crit Care Med 175: $1304-1345$

44. Miller MR, Hankinson J, Brusasco V, Burgos F, Casaburi R, et al. (2005) Standardisation of spirometry. Eur Respir J 26: 319-338.

45. Robinson PD, Latzin P, Verbanck S, Hall GL, Horsley A, et al. (2013) Consensus statement for inert gas washout measurement using multiple- and singlebreath tests. Eur Respir J 41: 507-522. 
Citation: Avramidou V, Hatziagorou E, Kampouras A, Georgopoulou V, Kirvasilis F, et al. (2017) Is Lung Clearance Index (LCl) Affected by the Severity of Lung Disease in CF? J Pulm Respir Med 6: 392. doi: 10.4172/2161-105X.1000392

Page 7 of 7

46. Singer F, Kieninger E, Abbas C, Yammine S, Fuchs O, et al. (2013) Practicability of nitrogen multiple-breath washout measurements in a pediatric cystic fibrosis outpatient setting. Pediatr Pulmonol 48: 739-746.

47. Horsley A (2009) Lung clearance index in the assessment of airways disease. Respir Med 103: 793-799.

48. Fuchs SI, Ellemunter H, Eder J, Mellies U, Grosse-Onnebrink J, et al. (2012) Feasibility and variability of measuring the Lung Clearance Index in a multicenter setting. Pediatr Pulmonol 47: 649-657.

49. Egger B, Jost K, Anagnostopoulou P, Yammine S, Singer F, et al. (2016) Lung clearance index and moment ratios at different cut-off values in infant multiplebreath washout measurements. Pediatr Pulmonol 51: 1373-1381.

50. Green K, Ejlertsen JS, Madsen A, Buchvald FF, Kongstad T, et al. (2016) Abbreviation modalities of nitrogen multiple-breath washout tests in school children with obstructed lung disease. Pediatr Pulmonol 51: 624-632.

51. Grønbæk J, Hallas HW, Arianto L, Pedersen K, Thomsen A, et al. (2016) New time-saving predictor algorithm for multiple breath washout in adolescents. Pediatr Res 80: 49-53.

52. Hannon D, Bradley JM, Bradbury I, Bell N, Elborn JS, et al. (2014) Shortened lung clearance index is a repeatable and sensitive test in children and adults with cystic fibrosis. BMJ Open Respir Res 1: e000031.

53. Yammine S, Singer F, Abbas C, Roos M, Latzin P (2013) Multiple-breath washout measurements can be significantly shortened in children. Thorax 68 : 586-587.

54. Verbanck S, Schuermans D, Van Muylem A, Melot C, Noppen M, et al. (1998) Conductive and acinar lung-zone contributions to ventilation inhomogeneity in COPD. Am J Respir Crit Care Med 157: 1573-1577.

55. Courtney JM, Bradley J, Mccaughan J, O'Connor TM, Shortt C, et al. (2007) Predictors of mortality in adults with cystic fibrosis. Pediatr Pulmonol 42: 525-532.

56. Long FR, Williams RS, Castile RG (2004) Structural airway abnormalities in infants and young children with cystic fibrosis. J Pediatr 144: 154-161.

57. Young C, Owens C (2012) 'To CT or not to CT? That is the question': Outcome surrogates for surveillance in childhood cystic fibrosis. Thorax 67: 471-472.

58. Fuchs SI, Gappa M, Eder J, Unsinn KM, Steinkamp G, et al. (2014) Tracking lung clearance index and chest CT in mild cystic fibrosis lung disease over a period of three years. Respir Med 108: 865-874.
59. Horsley AR, Davies JC, Gray RD, Macleod KA, Donovan J, et al. (2013) Changes in physiological, functional and structural markers of cystic fibrosis lung disease with treatment of a pulmonary exacerbation. Thorax 68: 532-539.

60. Stick S, Tiddens H, Aurora P, Gustafsson P, Ranganathan S, et al. (2013) Early intervention studies in infants and preschool children with cystic fibrosis: are we ready? Eur Respir J 42: 527-538.

61. Sonneveld N, Stanojevic S, Amin R, Aurora P, Davies J, et al. (2015) Lung clearance index in cystic fibrosis subjects treated for pulmonary exacerbations. Eur Respir J 46: 1055-1064.

62. Hatziagorou E, Avramidou V, Kirvassilis F, Tsanakas J (2015) Use of lung clearance index to assess the response to intravenous treatment in cystic fibrosis. Hippokratia 19: 47-52.

63. Simpson SJ, Ranganathan S, Park J, Turkovic L, Robins-Browne RM, et al. (2015) Progressive ventilation inhomogeneity in infants with cystic fibrosis after pulmonary infection. Eur Respir J 46: 1680-1690.

64. Horsley AR, Gustafsson PM, Macleod KA, Saunders C, Greening AP, et al. (2008) Lung clearance index is a sensitive, repeatable and practical measure of airways disease in adults with cystic fibrosis. Thorax 63: 135-140.

65. Demirkazik FB, Ariyürek OM, Özçelik U, Göçmen A, Hassanabad HK, et al. (2001) High resolution CT in children with cystic fibrosis: correlation with pulmonary functions and radiographic scores. Eur J Radiol 37: 54-59.

66. Edwards EA, Narang I, Li A, Hansell DM, Rosenthal M, et al. (2004) HRCT lung abnormalities are not a surrogate for exercise limitation in bronchiectasis. Eur Respir J 24: 538-544

67. Aurora P, Gustafsson P, Bush A, Lindblad A, Oliver C, et al. (2004) Multiple breath inert gas washout as a measure of ventilation distribution in children with cystic fibrosis. Thorax 59: 1068-1073.

68. Aurora P, Stanojevic S, Wade A, Oliver C, Kozlowska W, et al. (2011) Lung clearance index at 4 years predicts subsequent lung function in children with cystic fibrosis. Am J Respir Crit Care Med 183: 752-758.

69. Stanojevic S, Jensen R, Sundaralingam D, Salazar JG, Yammine S, et al. (2015) Alternative outcomes for the multiple breath washout in children with CF. J Cyst Fibros 14: 490-496. 